\title{
A New Model for an Augmented Reality Based Content (ARBC) (A Case Study on the Palestinian Curriculum)
}

\author{
Magdy S. Aqel \\ (Curriculum Department, Faculty of Education/Islamic University of Gaza, Palestine)
}

\begin{abstract}
The digital age has forced people to use technology, this distributed learning is found everywhere, both teachers and students are in need to use new strategies that based on technology such as mobile, Pc, iPad. Those means has the augmented reality as a suitable base and infrastructure. It's not acceptable to introduce the content in a traditional way while we live in the digital age that is filled of techno geeks students. This paper tries to introduce a new model for determining, using, and evaluating augmented reality based content. In this paper, I focused on the Palestinian curriculum and how to convert the static images and shapes into dynamic content. First, I divided the model into five steps; Analyses, determine, produce, use and evaluate. This model takes in account the educational theories such as constructivism and connectivism. Also, this model sees the students as the core of the content and learning process.
\end{abstract}

Keyword: eLearning, Augmented Reality(AR), Palestine curriculum

\section{Introduction}

The mobile industries and web based applications contributed in AR developing; learners need more information about any object and AR has the solution. AR is not only used in learning but also everywhere at markets, tourism, industry, and medicine and this is because of its cheap and easy to use.

In recent years, AR has been applied in various fields, such as E-learning, monument tour guides, and so on. Billinghurst et al. (2001) first used augmented reality technology to establish 3D books, allowing readers to see the figures and animation in books through a hand-held AR display (HHD). Miyashita et al. (2008) used AR in museum tours, where the tourists were guided through their visit by animated floating balloons. When the tourists reached the target objects, the exhibition objects' glass displayed the functions of AR. Lee et al. (2009).

Virtual Reality can be defined as "A human-computer interface in which the computer creates a sensory immersing environment that interactively responds to, and, is controlled by the behavior of the user".

The augmented reality mixes the real word with the computer environment, so "it is a type of technology which encourages the perception that user has of reality, introducing virtual elements in the same one. It's not limited just to the implementation of virtual elements as it also may erase objects which belong to the real world" (Gutiérrez \& Fernández, 2014). Azuma (1997) defines augmented reality as "an environment that includes both virtual reality and real-world elements. For instance, an AR user might wear translucent goggles; through these, he could see the real world, as well as computer-generated images projected on top of that world."

The augmented reality technology provides students with an interactive interface allowing them to learn and explore in different themed environments, in a more attractive and motivating way. Teachers are aware of the fact that the use of 3D images and any viewing technique for introducing contents helps and reinforces learning. In fact, several studies show that AR's implementation in the classroom helps in improving the learning process, increases student's motivation and eases the teacher's work (Martín-Gutiérrez \& Contero, 2011a).

AR maybe applied everywhere with a simple use of technology (Rahardja, Wu, Thalmann \& Huang, 2008) (Henderson \& Feiner, 2011) as well as walkthroughs for touristic route (Torpus, 2005).

An augmented reality (AR) has the ability to give the user the sense of the real world while interacting with the virtual and physical object Azuma (1997). AR technology has a promising potential that can be used in enhancing the physical storybook by augmenting the book pages with graphic, animations and audio (Dayang etal.,2012

\section{Literature Review}

Liarokapis et al. (Liarokapis et al., 2002) proposed a Multimedia Augmented Reality Interface (MARIE) E-Learning as shown fig (1), applied to engineering education, in order to enhance the traditional teaching and learning methods. The AR system uses virtual multimedia to interact with users and fits the tabletop environment. MagicBook (Billinghurst et al., 2001) exploits AR to design a set of books for users to read. It is like a normal paper book, but specially, the content in the book is made up of 3D animation, presented by AR, which shows the information from the book. A book is a real object while its content is a virtual object. 
Therefore, users can use handheld HMD to experience the AR scene in Magic Book. This reading method can help users turn their imaginary world into reality and then inspire more imagination in reading.

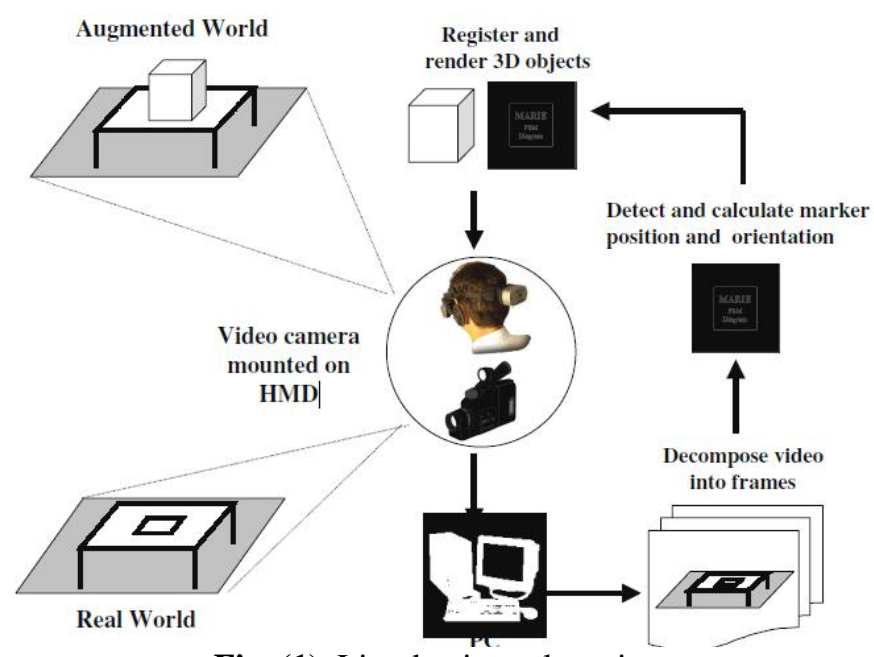

Fig. (1). Liarokapis et al. project.

Dünser and Hornecker (Dünser \& Hornecker, 2007) observe the condition of students' reading AR textbooks as shown in fig. (2). Moreover, they probe examining how the students from 6 to 7 years old operate the novel interactive teaching media. When students use paddle to interact with the AR textbook, the monitor will display text, sound, avatar etc. related to AR textbooks. The main focus is on the students' reaction while they are using touchable interactive interface. This reading method can help users in turning their imaginary world into reality and then inspire more imagination in reading.

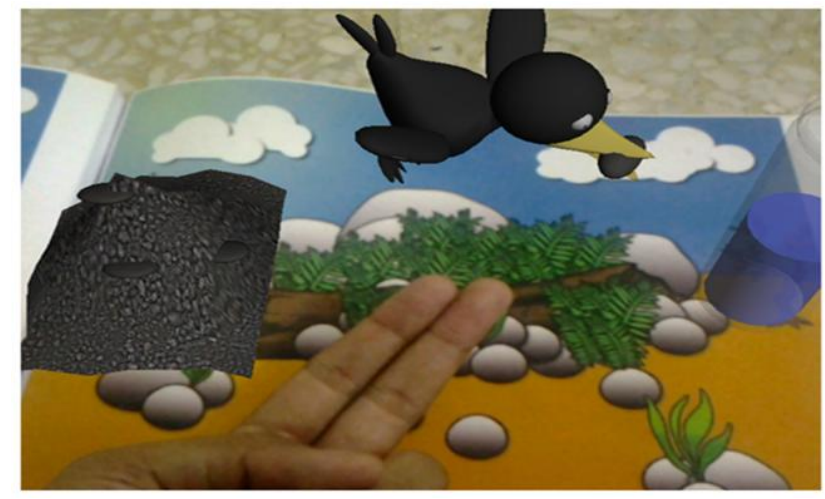

Fig. (2). Dünser and Hornecker project.

Luis et al. (2013) developed PBL system which required collaborative environments to share information and the use of Internet to share knowledge. They used AR permit to start the students' research outside the laboratory. As a result, the students became familiar with instruments before working at real environments.
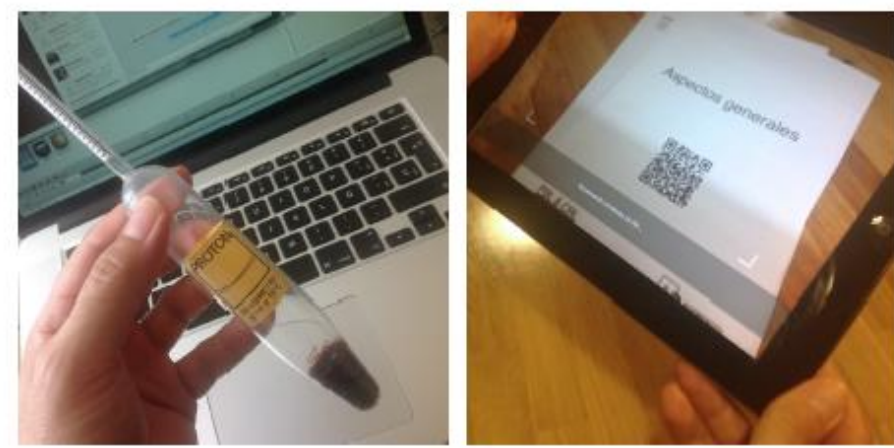

Fig (3). Luis et al. project

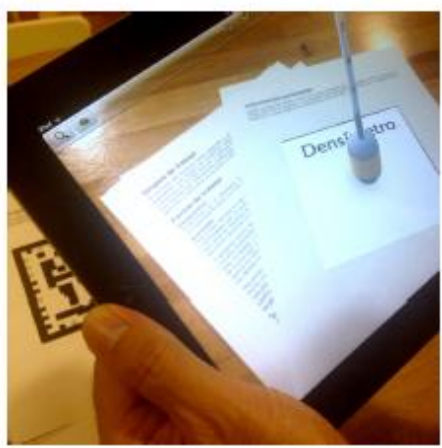

www.iosrjournals.org

96 | Page 


\section{The Augmented Realty Environment}

An augmented reality based content is not difficult as many teachers think. all what we want is camera, Pc/laptop/ mobile, marker and object.

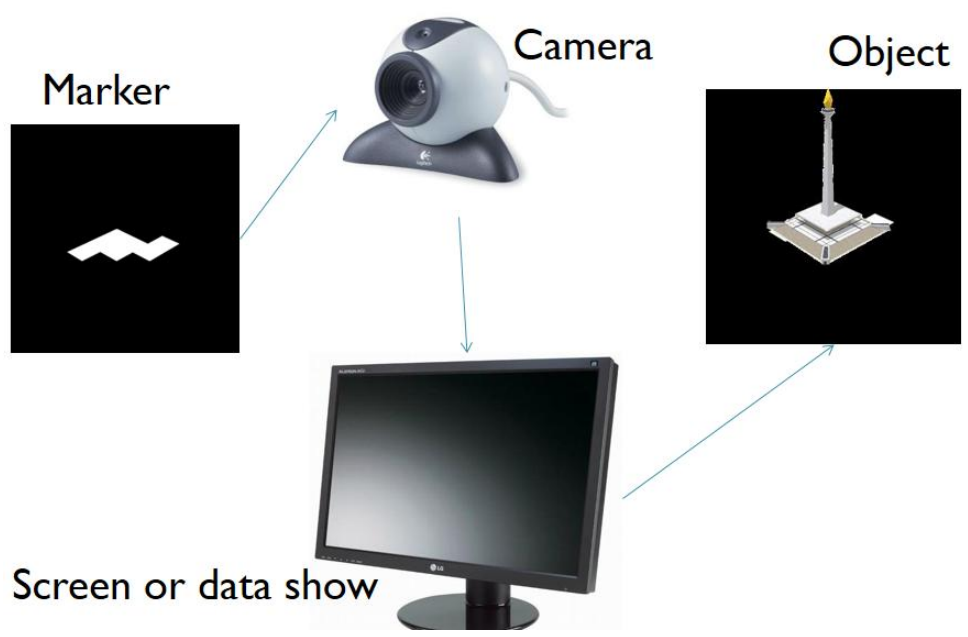

Fig. (4) AR components

\section{AR Environment description}

Marker: Any sign or shape which can be drawn by the teacher, can be done by a simple design application. It has to be simple and it has to be often in monocolor. Although there's no direct relation between the marker and the object, I myself prefer to use significant marker. Moreover, it is better to be clear and close to the camera marker always relates to the shape or image from the content.

We have to know that the marker may be free to move by hand or it may be fixed on a book.
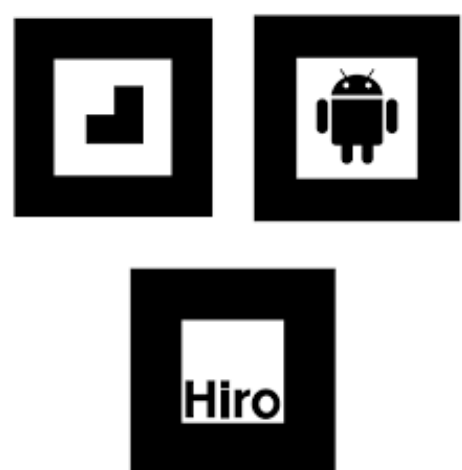

Fig. (5) marker

Object: Can be image, 3D model, sound, video or text, it appears when the marker is defined to the content. In this case, the object appears over the marker and takes its dimensions (X, Y, Z).
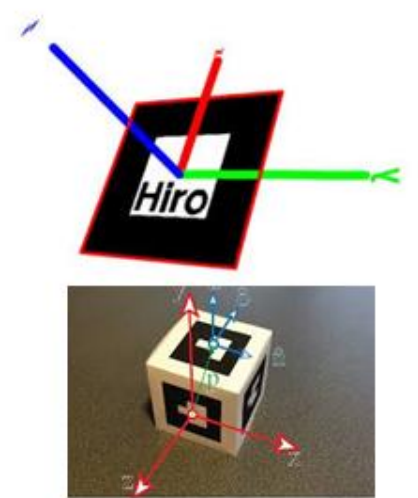

Fig. (6) objects

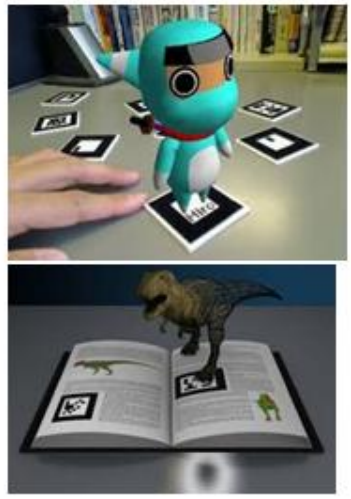

www.iosrjournals.org 


\section{Connecting methods}

The main question here is how we connect the marker with the object, The AR is often based on the mobile application or PC. There are many SW for pc such as (ARBuilder but they are easier for mobile because there are many ready-made applications for AR like (4D elements, Animals 4D) fig (7), also there are many mobile applications to that task such as (Aurasma) fig (8).
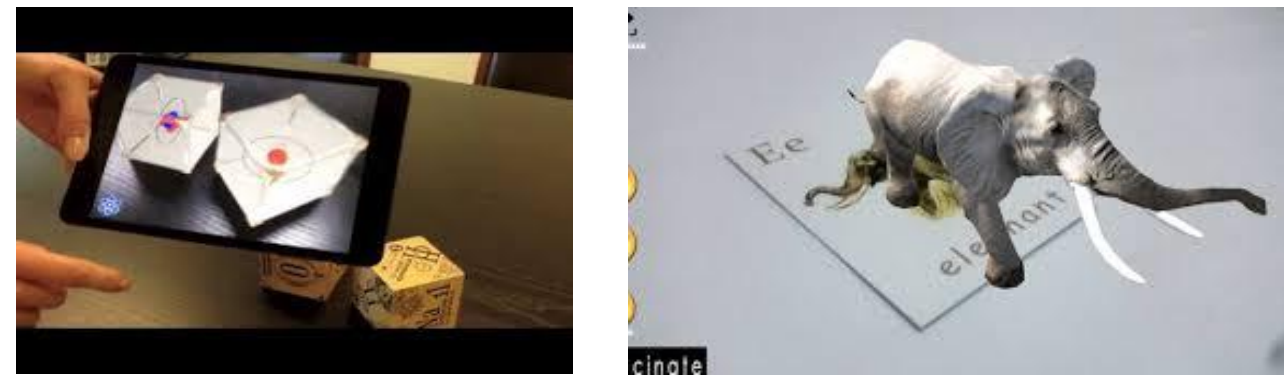

Fig. (7) Ready-made applications

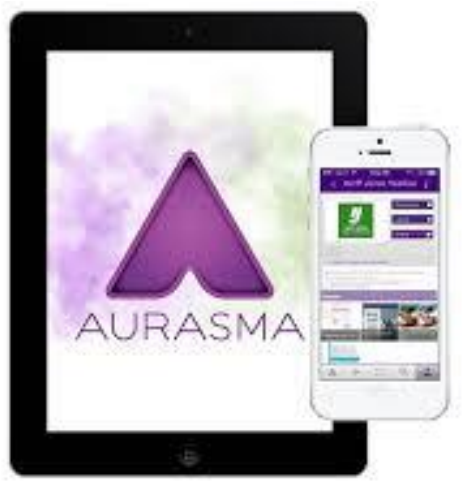

Fig. (8) User-made applications

Camera: it's not necessary to use HD camera; the teacher can use laptop camera, the more quality a camera has, the quicker the marker becomes.

Screen/data show: it's the projector for the new augmented content.

\section{Methodology}

The researcher used content analyses approach and developing approach to establish a new augmented reality based content(ARBC) model. all study steps are applied on the Palestinian curriculum. The Model general steps are as shown in fig. (9).

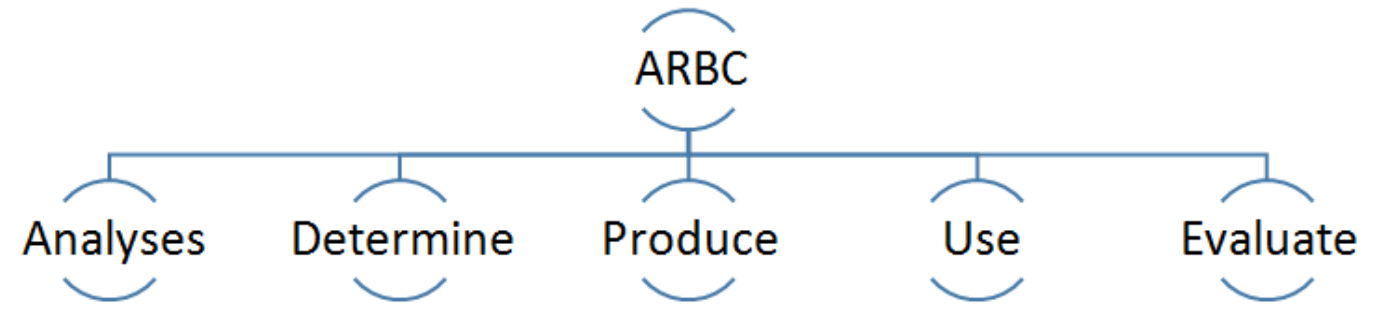

Fig. (9). ARBC Model Steps

\section{Analyses:}

This step starts from a real need of using AR. This means when the teacher feels that students' skills or achievements are weak and they can't understand the objectives of the content, the teacher starts to think about a new method or technique to help the students.

\section{Determine:}

In this step, the teacher has to:

A. Detect the objectives of the content in a clear way.

B. Determine the teacher's /students' roles.

C. Describe the required object and its colors, dimensions and movements. 
D. Determine the authoring SW which is needed to produce the object.

E. Describe the learning environment that includes (light, electricity, safety and ventilation).

F. Determine the core components for applying AR such as:

- Pc/lab top/iPad.

- Data show projector.

- Amplifier.

- HD camera, or Kinect camera.

- $\quad$ AR SW (EX. AR builder SW, Aurasma).

3. Produce:

In this step, we start producing AR object in this tasks:

A. Design the object by a suitable SW such as (3DMAx, Maya, Google sketch up).

B. Design the marker; this is often designed in monocolor and is related to the object.

C. Use a suitable SW for connecting the marker with object.

4. Use:

In this step, we start applying AR in class; teachers have to train the students to use AR techniques. The students' interaction is very important also teachers have to detect these required points:

A. Learning strategies.

B. Students' interaction.

C. Reinforcements.

D. Continues Motivation.

5. Evaluate:

A. Feedback and developing are very important AR model. In in this step SW and objectives have to be evaluated, Moreover, the following questions should be answered:

B. We want to examine whether the used SW run correctly without bugs or not?

C. Whether the object appeared in a correct way for the students or not? And whether the students understood the content or not?

\section{ARBC test}

The new model was tested on the Palestinian curriculum/ math unit according to these steps:

\section{Analyses:}

In this step, we search for the need of AR, so we look for any static image or shape which can be converted into a dynamic object. In the Palestinian curriculum, there are many images and shapes, but of course, all of them are in the static case. Our object is to discover the lack of AR. I choose the math book for $5^{\text {th }}$ grade as a case study of Palestine curriculum.

\section{Determine:}

After the content analyses, I found some shapes (Cuboid, cube, cone, cylinder, ball and pyramid) as shown in Fig (10). How these shapes will be if we use if we use AR. Students can move every shape free in 3D, also they will be able to determine the base, the height and the long in an easy way.

Data show projector, HD camera and (ARBuilder) were available at the students' class.
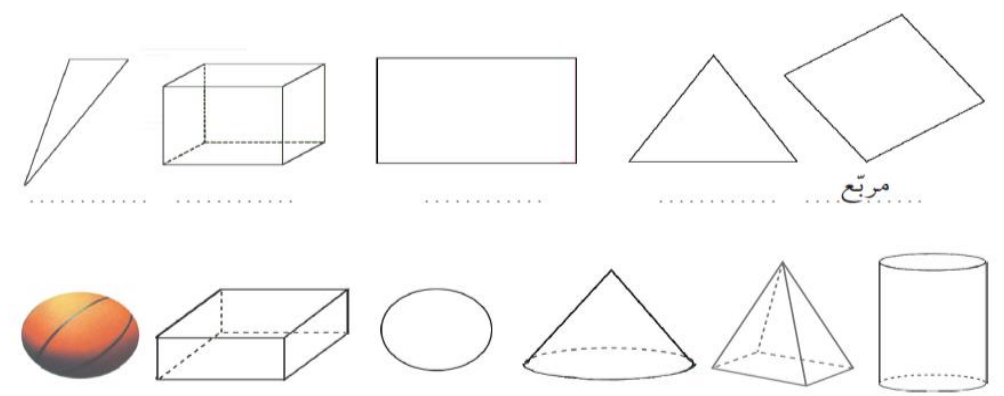

Fig. (10). Geometric shapes at $5^{\text {th }}$ grade Palestinian math curriculum

\section{Produce:}

Google sketup was used to produce the need geometrics, fig. (11), an example for the cone object. The marker was created in a simple way fig. (12), ARBuilder application was used to connect the object with the marker. 


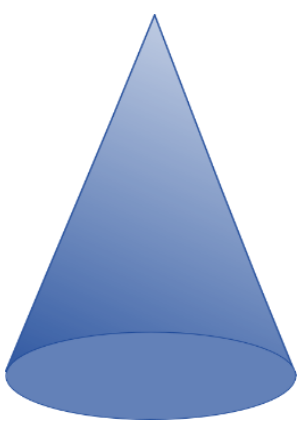

Fig. (11) cone by google sketup

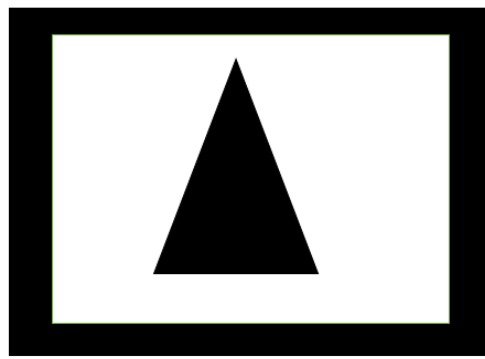

fig. (12) cone marker

\section{Use:}

At the class room, AR based content was shown to the students by using laptop and data show project. All the student tried to interact with the geometrical object in 3D, and they moved the object in all directions.

\section{Evaluate:}

Achievement test with (10) MCQ question was used to examine the students understanding at geometry lesson. The mean scores for the students was $(95.4 \%)$, and the students were very surprised.

\section{Conclusions}

This paper found a new model for using AR in learning. ARBC consisted of five steps (Analyses, determine, produce, use and evaluate), also the researcher tested this mode on the Palestinian math curriculum, and the result was very awesome.

\section{References}

[1] Azuma, R. (1997). A Survey of Augmented Reality Presence: Teleoperators and Virtual Environments,6(4), pp. 355-385.

[2] Billinghurst, M., Kato, H., \& Poupyrev I. (2001). The MagicBook: A transitional AR interface, Computer and Graphic, Vol. 25, pp. 745-753.

[3] Dayang Rohaya, AR, Wannisa Matcha, SS, Mohd Yunus N.(2012) Design and Development of an Interactive Augmented Reality Edutainment Storybook for Preschool, IERI Procedia, Vol 2,pp. 802-807, ISSN 2212-6678.

[4] Dünser, A. \& Hornecker, E. (2007). Lessons from an AR book study. Proceedings of the First International Conference on Tangible and Embedded Interaction, pp. 179-182.

[5] Gutiérrez, J. M., \& Fernández, M. D. M. (2014). Augmented reality environments in learning, communicational and professional contexts in higher education. Digital Education Review, 61-73.

[6] Henderson, S. \& Feiner, S. (2011). Exploring the Benefits of Augmented Reality Documentation for Maintenance and Repair. IEEE Transactions on Visualization and Computer Graphics, 17(10), pp. 1355-1368.

[7] Lee, S. H., Choi, J. \& Park, J. I. (2009). Interactive e-learning system using pattern recognition and augmented reality, IEEE Transactions on Consumer Electronics, 883-890.

[8] Liarokapis, F., Petridis, P., Lister, P. F. \& White, M. (2002). Multimedia Augmented Reality Interface for E-learning (MARIE), World Trans. on Engineering and Technology Education, Vol. 1, No. 2, pp. 173-176 2002.

[9] Luis, C. E. M., Mellado, R. C., \& Díaz, B. A. (2013). PBL methodologies with embedded augmented reality in higher maritime education: augmented project definitions for chemistry practices. Procedia Computer Science, 25, 402-405.

[10] Martín-Gutiérrez, J., Saorín, J.L., Contero, M., Alcañiz, M., Pérez-López, D. C. \& Ortega, M.(2010). “Design and Validation of an Augmented Book for Spatial Abilities Development in Engineering Students”. Computer \& Graphics, 34(1), pp. 77-91.

[11] Miyashita T, Kubik S, Lewandowski G, Guzowski JF (2008).Networks of neurons, networks of genes: an integrated view of memory consolidation. Neurobiol Learn Mem 89:269-284.

[12] Rahardja, S., Wu, E., Thalmann, D. \& Huang, Z. (2008). Visualization of intelligent maintenance systems through mixed reality. In Proceedings of the 7th International Conference on Virtual Reality Continuum and its Applications in Industry. Singapore:ACM Press.

[13] Torpus, J. (2005). LifeClipper. In Proceeding of the International Conference on Virtual Systems and Multimedia. Belgium [Accessed: 23/04/2014] http://www.torpus.com/lifeclipper 